\title{
Development of Isothermal Recombinase Polymerase Amplification Assay for Rapid Detection of Porcine Circovirus Type 2
}

\author{
Yang Yang, Xiaodong Qin, Yingjun Sun, Guozheng Cong, Yanmin Li, and Zhidong Zhang \\ State Key Laboratory of Veterinary Etiological Biology, Lanzhou Veterinary Research Institute, \\ Chinese Academy of Agricultural Sciences, Xujiaping 1, Lanzhou, Gansu 730046, China
}

Correspondence should be addressed to Zhidong Zhang; zhangzhidong@caas.cn

Received 6 December 2016; Accepted 13 March 2017; Published 23 March 2017

Academic Editor: Cristina Domingo

Copyright (C) 2017 Yang Yang et al. This is an open access article distributed under the Creative Commons Attribution License, which permits unrestricted use, distribution, and reproduction in any medium, provided the original work is properly cited.

\begin{abstract}
Porcine circovirus virus type II (PCV2) is the etiology of postweaning multisystemic wasting syndrome (PMWS), porcine dermatitis, nephropathy syndrome (PDNS), and necrotizing pneumonia. Rapid diagnosis tool for detection of PCV2 plays an important role in the disease control and eradication program. Recombinase polymerase amplification (RPA) assays using a realtime fluorescent detection (PCV2 real-time RPA assay) and RPA combined with lateral flow dipstick (PCV2 RPA LFD assay) were developed targeting the PCV2 ORF2 gene. The results showed that the sensitivity of the PCV2 real-time RPA assay was $10^{2}$ copies per reaction within $20 \mathrm{~min}$ at $37^{\circ} \mathrm{C}$ and the PCV2 RPA LFD assay had a detection limit of $10^{2}$ copies per reaction in less than $20 \mathrm{~min}$ at $37^{\circ} \mathrm{C}$. Both assays were highly specific for PCV2, with no cross-reactions with porcine circovirus virus type 1 , foot-and-mouth disease virus, pseudorabies virus, porcine parvovirus, porcine reproductive and respiratory syndrome virus, and classical swine fever virus. Therefore, the RPA assays provide a novel alternative for simple, sensitive, and specific identification of PCV2.
\end{abstract}

\section{Introduction}

Porcine circovirus virus (PCV) is a small, nonenveloped DNA virus with diameter of $17 \mathrm{~nm}$, which is divided into two distinct genotypes (PCV1 and PCV2) [1]. PCV2 is a major causative agent of postweaning multisystemic wasting syndrome (PMWS) which is characterized by progressive weight loss, respiratory impairment, nephropathy syndrome, and congenital tremor, and it can affect nursery and fattening pigs all around the world [2-5]. Furthermore, as PCV2 is an immunosuppressive virus, it makes the pig more vulnerable to other viruses and bacteria. Investigations show that PCV2 commonly exists in pig populations [6].

Polymerase chain reaction- (PCR-) based assays including conventional PCR and real-time PCR assays were developed and widely used in the laboratory for detection of PCV2 DNA [7-12]. These PCR-based assays have played a crucial role in monitoring and controlling PCV2. However, these assays require sophisticated equipment and well-trained technician, which limit the application of PCRbased methods in field and poorly equipped technicians.

An isothermal detection method, recombinase polymerase amplification (RPA), has been developed as an alternative to PCR assay which can amplify nucleic acids at $37^{\circ} \mathrm{C}-39^{\circ} \mathrm{C}$ within $20 \mathrm{~min}$. RPA has been developed for veterinary importance viruses detection, including porcine parvovirus virus [13], avian influenza virus [14], bovine viral diarrhea virus [15], canine parvovirus type 2 [16], foot-andmouth disease virus [17], and Orf virus [18, 19]. In this study, we developed fluorescent probe-based real-time RPA assay (PCV2 real-time RPA assay) and RPA assay united with LFD (PCV2 RPA LFD assay) to detect PCV2.

\section{Materials and Methods}

2.1. Virus and Clinical Specimens. All viruses used in this study are listed in Table 2. Sixty-five clinical samples (spleen, 
TABLE 1: RPA primers and probes designed in this research.

\begin{tabular}{|c|c|c|}
\hline Name & Sequence $\left(5^{\prime}-3^{\prime}\right)$ & Genome location (DQ231511) \\
\hline PCV2 RPA Fe1 & ATACCATAACCCAGCССТTCTCCTACCACTCCCGC & $443-477$ \\
\hline PCV2 RPA Fe2 & ATAACCСAGCССТTCTССТАССАСТCССGСТАСТT & $448-482$ \\
\hline PCV2 RPA Fe3 & AAACCTGTCCTAGATTCCACTATTGATTACTTCCA & $490-524$ \\
\hline PCV2 RPA Re1 & TTGTATTCCTGGTCGTATATACTGTTTTCGAACGC & $601-635$ \\
\hline PCV2 RPA Re2 & ATATTGTATTCCTGGTCGTATATACTGTTTTCGAA & $604-638$ \\
\hline PCV2 RPA Re3 & TTACACGGATATTGTATTCCTGGTCGTATATACTG & $612-646$ \\
\hline \multirow[t]{2}{*}{ PCV2 RPA Pe } & ATTACTTCCAACCAAACAACAAAAGAAATCAGCTG & $515-569$ \\
\hline & (FAM-dT)G(THF)C(BHQ1-dT)GAGACTACAAACTGC-C3 space & \\
\hline PCV2 RPA Fn1 & ATACСАTAACССАGСССТТСТССТАССАСТСССGC & $443-477$ \\
\hline PCV2 RPA Fn2 & 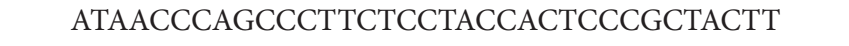 & $448-482$ \\
\hline PCV2 RPA Fn3 & AAACCTGTCCTAGATTCCACTATTGATTACTTCCA & $490-524$ \\
\hline PCV2 RPA Rn1 & biotin-TTGTATTCCTGGTCGTATATACTGTTTTCGAACGC & $601-635$ \\
\hline PCV2 RPA Rn2 & biotin-ATATTGTATTCCTGGTCGTATATACTGTTTTCGAA & $604-638$ \\
\hline PCV2 RPA Rn3 & biotin-TTACACGGATATTGTATTCCTGGTCGTATATACTG & $612-646$ \\
\hline \multirow[t]{2}{*}{ PCV2 RPA Pn } & FAM-TACTTCCAACСAAACAACAAAAGAAATCAGCTGTG & $517-567$ \\
\hline & -THF-CTGAGACTACAAACT-C3 space & \\
\hline
\end{tabular}

TABLE 2: Evaluation of the specificity of PCV2 real-time RPA assay and PCV2 RPA LFD assay.

\begin{tabular}{|c|c|c|c|c|c|}
\hline Virus family & Virus species & Virus strain & Real-time RPA & RPA LFD & Real-time qPCR \\
\hline \multirow{3}{*}{ Circoviridae } & PCV2 & NX strain & $6 \mathrm{~min}$ & + & $15(\mathrm{CT})$ \\
\hline & PCV2 & CQ strain & $5.6 \mathrm{~min}$ & + & $14(\mathrm{CT})$ \\
\hline & PCV1 & JL strain & - & - & - \\
\hline Arteriviridae & PRRSV & $\mathrm{CH}-1 \mathrm{R}$ & - & - & - \\
\hline Herpesviridae & PRV & $\mathrm{Fa}$ & - & - & - \\
\hline Flaviviridae & CSF & C-strain & - & - & - \\
\hline Parvoviridae & PPV & AV30 & - & - & - \\
\hline Picornaviridae & FMDV & FMDV/O/CHA & - & - & - \\
\hline
\end{tabular}

${ }^{+}$Positive; ${ }^{-}$negative.

inguinal lymph node, tonsil, lung, and serum) were collected from suspected PCV2 infection pigs from eight pig farms in Shandong Province (China), thirty-seven clinical samples (inguinal lymph node, tonsil, lung, and serum) were collected from Gansu Province (China), and ten PCV1 positive samples were conserved in our laboratory, confirmed by real-time qPCR [20] and Sanger dideoxy sequencing.

2.2. Generation of DNA Standard and DNA Extraction. The PCV2 ORF2 gene segments (320 bp, ranging from $359 \mathrm{bp}$ to 678 bp of DQ231511) named pPCV2/RPA were synthesized by Genewiz (Suzhou, China) as DNA standard. Viral RNA/DNA was isolated by a TaKaRa Viral Mini kit (TaKaRa, China) according to the manufacturer's instructions and eluted in a volume of $50 \mu \mathrm{L}$. In order to use the RPA assay in the field, DNA extraction was also performed by innuPREP MP basic kit A (Jena Analytik, Jena, Germany) combined with magnetic bead separation rack following the manufacturer's instructions.

2.3. Design of the Primers and Probe of RPA. After aligning the ORF2 gene consensus sequence of KR559725.1,
KR559695.1, KM455975.1, KP768481.1, JN181905.1, JN181902.1, KF850461.1, KC620515.1, KF035059.1, KF951567.1, KF951570.1, KM624031.1, and JQ002672.1, we designed PCV2-specific RPA primers and probes in accordance with TwistDx RPA kits guidelines (Cambridge, United Kingdom). The sequences of designed probe and primers were summarized in Table 1.

2.4. Real-Time qPCR Assay. Real-time qPCR assay for detection of PCV2 DNA and PCV1 DNA were both performed on Agilent Mx3005P thermocycler machine (Life Technologies, USA) as previously described $[20,21]$. The primers PCV2 F ( $5^{\prime}$-ATGGCGGGAGGAGTAGTTT- $\left.3^{\prime}\right)$ and PCV2 R $\left(5^{\prime}\right.$ CCCTTTGAATACTACAGCG- $3^{\prime}$ ) were used to amplify a $171 \mathrm{bp}$ fragment within ORF2 region of the PCV2 genome. The detection limit was 80 copies per reaction, and it was specific for the PCV2. The primers for PCV1 DNA were as follows: PCV1 F (5'-GTCAGTGAAAATGCCAAGCAA$\left.3^{\prime}\right)$ and PCV1 R ( $5^{\prime}$-CCAAACCTTCCTCTCCGCA- $\left.3^{\prime}\right)$. The length of amplified products was $152 \mathrm{bp}$. The detection limit was 100 copies per reaction, and it was specific for PCV1. 
2.5. Recombinase Polymerase Amplification. Probe-based PCV2 real-time RPA assay was performed with TwistAmp exo kit (TwistDx, Cambridge, United Kingdom) on Agilent Technologies Mx3005P thermocycler (Life technologies, USA). The PCV2 real-time RPA assay was carried out as described below: $4 \mathrm{x}$ rehydration buffer, $120 \mathrm{nM}$ real-time RPA probe, $420 \mathrm{nM}$ real-time RPA primes, $2 \mu \mathrm{L}$ DNA template, and $14 \mathrm{mM}$ magnesium acetate. Fluorescence intensity of FAM was measured once every 20 seconds. PCV2 RPA LFD assay was performed with TwistAmp nfo kit (TwistDx, Cambridge, United Kingdom) combined with lateral flow dipstick (Milenia Biotec GmbH, Germany) in a water bath at $37^{\circ} \mathrm{C}$. After $20 \mathrm{~min}$ incubation, $2 \mu \mathrm{L}$ of amplification product was diluted in $198 \mu \mathrm{L}$ of the assay buffer.

2.6. Sensitivity and Specificity of PCV2 Real-Time RPA and RPA LFD Assays. A dilution range from $10^{6}$ to $10^{1}$ copies per reaction of the recombinant plasmid pPCV2/RPA DNA was used to evaluate the dynamic range of PCV2 real-time RPA assay in eight replicates. The detection limit of PCV2 RPA LFD assay was tested by a dilution series of pPCV2/RPA DNA, and the amplicons were also evaluated by agarose gel electrophoresis. In evaluating specificity of the developed PCV2 real-time RPA assay and RPA LFD assay, the reactions were evaluated with PCV2/NX, PCV2/CQ, PCV1/JL, $\mathrm{PRRSV} / \mathrm{CH}-1 \mathrm{R}, \mathrm{CSFV} / \mathrm{c}$-strain, $\mathrm{PRV} / \mathrm{Fa}, \mathrm{PPV} / \mathrm{AV} 30$, and $\mathrm{FMDV} / \mathrm{O} / \mathrm{CHA}$ in three replicates.

\section{Results}

3.1. Sensitivity and Specificity of PCV2 Real-Time RPA Assay. After running the PCV2 real-time RPA assay with different primer and probe combinations, PCV2 RPA F3/PCV2 RPA R1 combines with PCV2 RPA Pe which were used as they yielded the highest amplification efficiency (Table 1, Figure 1). The PCV2 real-time RPA assay was sufficiently sensitive for detecting $10^{2}$ copies per reaction within $20 \mathrm{~min}$ at $37^{\circ} \mathrm{C}$ (Figures 2(a) and 2(b)). The limit of PCV2 realtime RPA assay detection in $95 \%$ was $10^{2}$ copies per reaction of pPCV2/RPA (Figure 2(c)). In evaluating the specificity of PCV2 real-time RPA assay, no cross-reactions were observed with PCV1/JL, PRRSV/CH-1R, CSFV/c-strain, $\mathrm{PRV} / \mathrm{Fa}, \mathrm{PPV} / \mathrm{AV} 30$, and FMDV/O/CHA and positive signal was only observed with $\mathrm{PCV} 2 / \mathrm{NX}$ and $\mathrm{PCV} 2 / \mathrm{CQ}$ strain (Table 2).

3.2. Sensitivity and Specificity of PCV2 RPA LFD Assay. The sensitivity results showed that the detection limit of PCV2 RPA LFD assay was $10^{2}$ copies per reaction of the recombinant plasmid pPCV2/RPA DNA (Figure 4(a)), and the amplicon in the PCV2 RPA LFD assay (146bp) was also tested by subsequent visualization with $3 \%$ agarose gel electrophoresis (Figure 4(b)). In evaluating the specificity of PCV2 RPA LFD assay, no cross-reactions were observed with other important viruses of pigs as described above (Figure 5(a)), which were also confirmed by the agarose gel electrophoresis (Figure 5(b)).

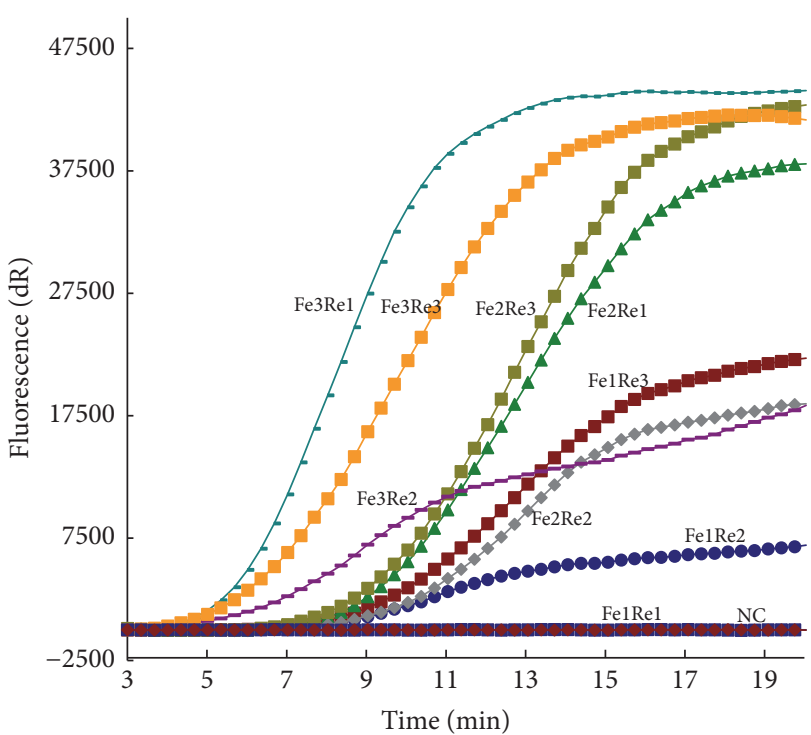

FIGURE 1: Optimal primers and probe combinations of PCV2 real-time RPA assay. The amplification results of nine different combinations of primers with the probe PCV2 RPA Pe are shown.

3.3. Performance of PCV2 Real-Time RPA Assay and PCV2 RPA LFD Assay on Clinical Samples. The practicality of both PCV2 real-time RPA assay and PCV2 RPA LFD assay was evaluated with clinical tissue samples $(n=102)$. The results were then compared with PCV2 real-time qPCR assay. Among these clinical samples, 31 samples were tested as positive by PCV2 real-time $\mathrm{QPCR}$ assay (CT value ranging from 19 to 30 ). All of these 31 samples were determined to be positive by both PCV2 real-time RPA assay (threshold time ranging from 5.6 to 9.3) and PCV2 RPA LFD assay. Based on total samples examined, the sensitivity and the specificity of both PCV2 real-time RPA assay and PCV2 RPA LFD assay for identification of PCV2 were $100 \%$ and $100 \%$, respectively, when compared to PCV2 real-time qPCR (Table 3). The PCV2 real-time RPA assay and PCV2 RPA LFD assay were also evaluated with PCV1 positive samples $(n=10)$, and the results showed that all the samples were PCV2 negative. The extraction effects of innuPREP MP basic kit were tested with these PCV2 positive tissue samples, and results showed this kit performed well (Table 4). This DNA/RNA extraction kit combining with RPA assay could be used in the field or in not well-equipped laboratories.

\section{Discussion}

In this study, RPA assays were developed for rapid and specific detection of PCV2. The most optimal detection conditions of PCV2 RPA LFD assay were explored with different reaction temperature and time. The results showed that it amplified well from $30^{\circ} \mathrm{C}$ to $45^{\circ} \mathrm{C}$. The amplification products could be detected when the reaction time was more than $10 \mathrm{~min}$ (Figures 3(a) and 3(b)). Therefore, the PCV2 RPA LFD assay performed in a simple water bath at $37^{\circ} \mathrm{C}$ for 20 min arbitrarily. A visible band on the LFD strip gives 


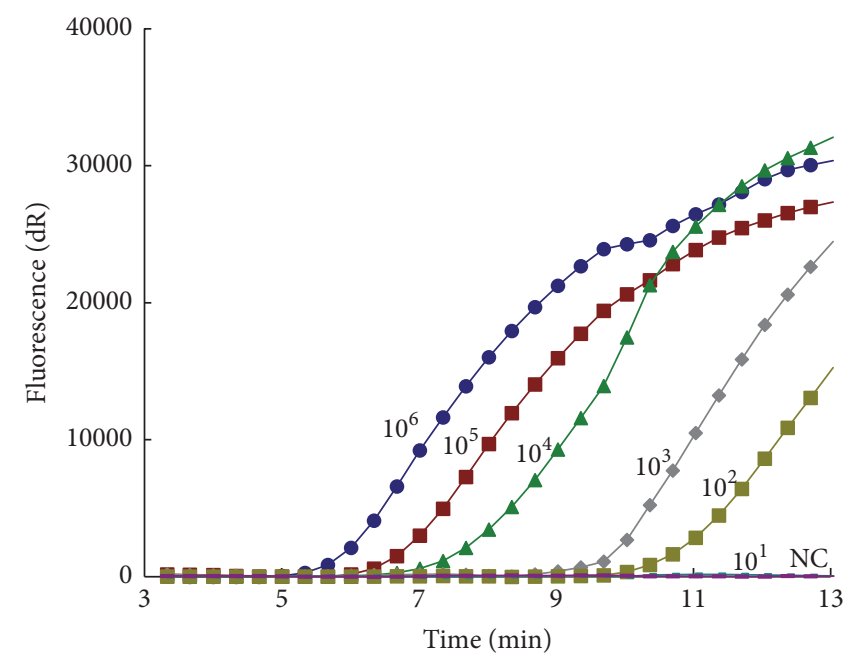

(a)

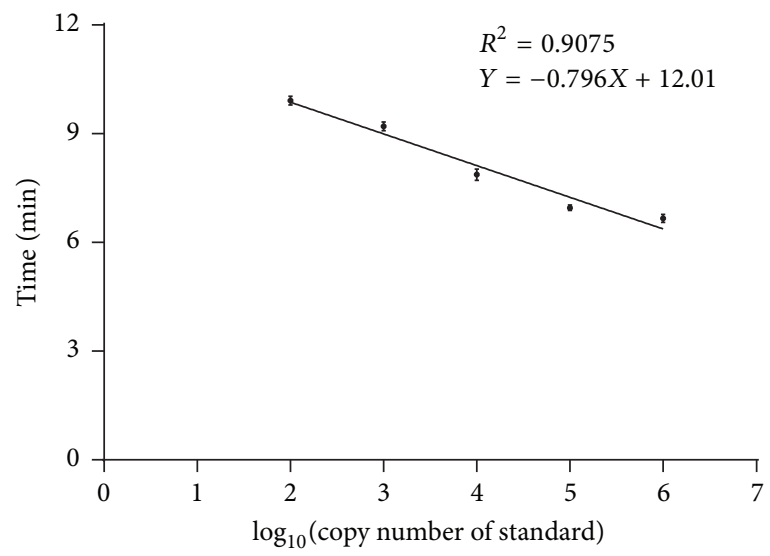

(b)

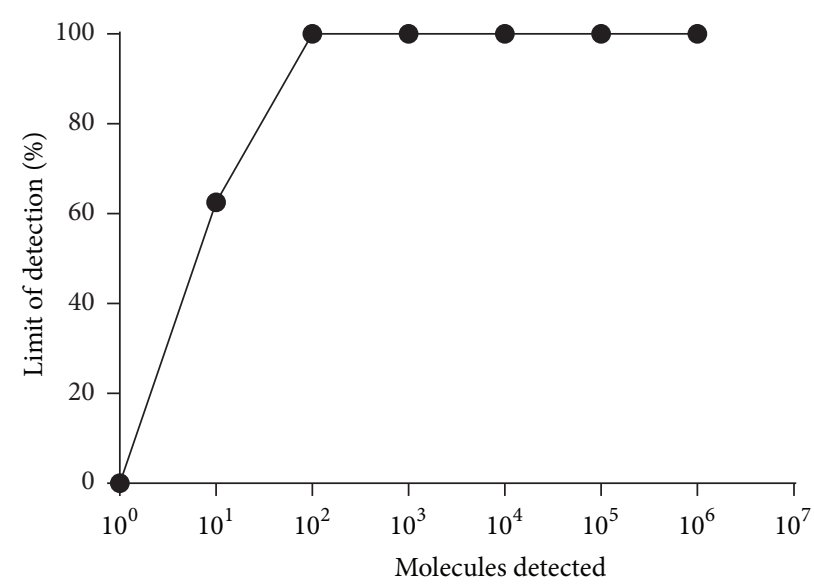

(c)

FIGURE 2: The sensitivity of PCV2 real-time RPA assay. (a) Fluorescence performance via real-time test using a dilution range of pPCV2/RPA. (b) Reproducibility of the PCV2 real-time RPA assay according to eight test runs. (c) Probit regression analysis was done on data from the eight runs of PCV2 real-time RPA assay.

Reaction temperature $\left({ }^{\circ} \mathrm{C}\right)$

$\begin{array}{lllllllll}15 & 20 & 25 & 30 & 35 & 37 & 40 & 45 & 50\end{array}$

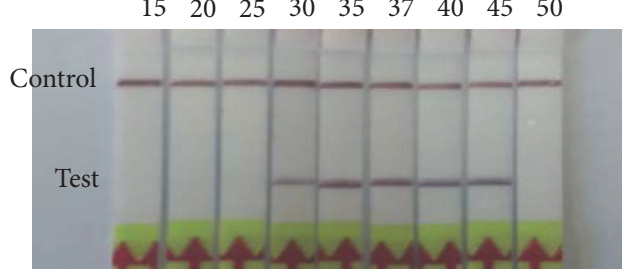

(a)

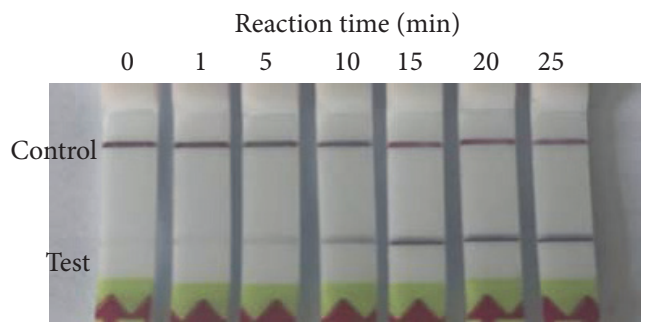

(b)

FIGURE 3: Optimal detection conditions of PCV2 RPA LFD assay. (a)The assay works in a broad range of temperatures. (b) After 10 min of amplification, the test line is visible on the lateral flow dipstick.

a clear positive/negative result which can be easily read by the naked eyes without any training. In the developed PCV2 real-time RPA assay, a real-time PCR machine is available in our laboratory. A simple ESEQuant TS2 device (Qiagen, Germany) is also available in PCV2 real-time RPA assay [14, 17]. This device is simpler and cheaper than the real-time PCR machine, and it could be used conveniently in field as it could be charged by battery. Additionally, a commercially magnetic bead-based DNA/RNA extraction kit could combine with RPA assay without any instrument. These features made PRA more applicable for onsite testing or rapid diagnosis in not well-equipped laboratories. 


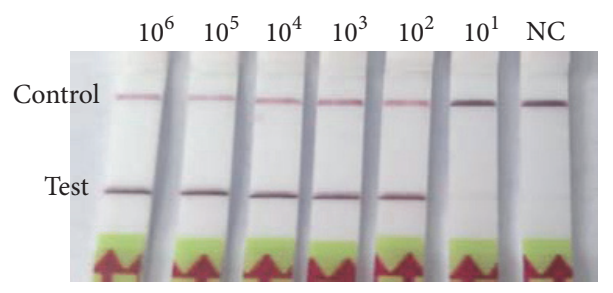

(a)

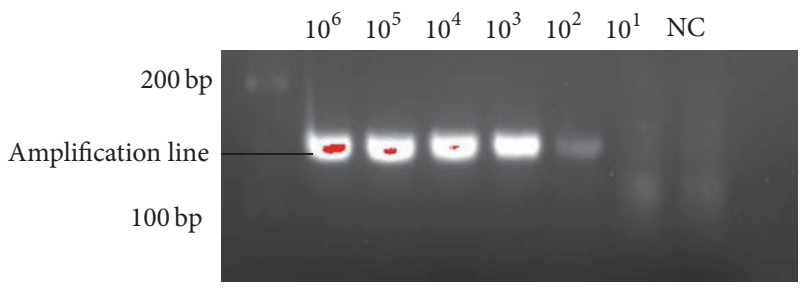

(b)

FIGURE 4: Evaluation of the sensitivity of PCV2 RPA LFD assay. (a) In the lateral flow format (PCV2 RPA LFD) the sensitivity was $10^{2}$ copies of the standard DNA. (b) Positive PCV2 RPA LFD reaction products (146 bp) could be detected on a stained agarose gel (3\%).

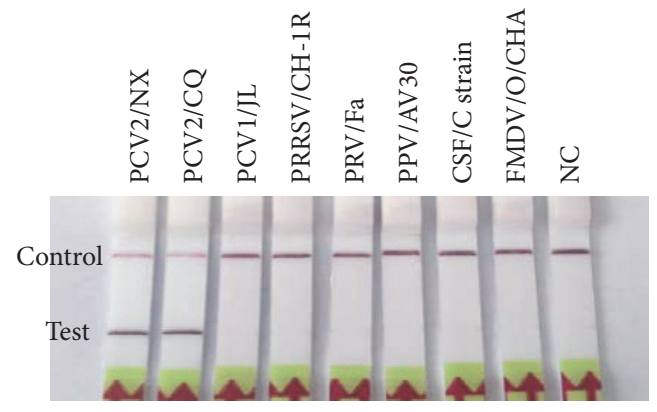

(a)

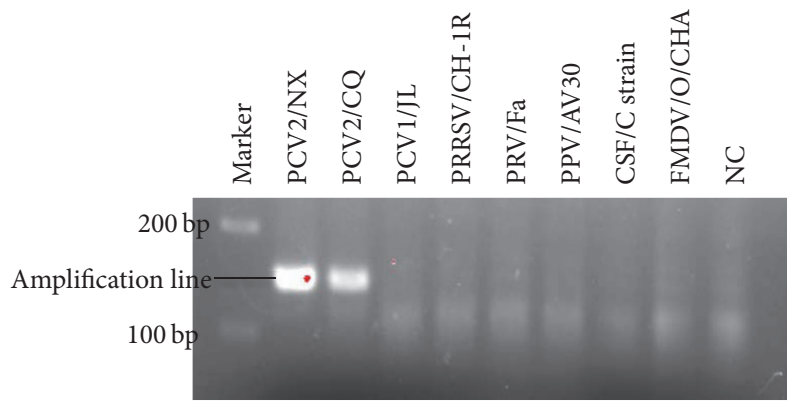

(b)

Figure 5: (a) Specificity test results of PCV2 RPA LFD assay using total DNA extracted from PCV2 virus and other virus. (b) Positive PCV2 RPA LFD reaction products (146 bp) could be detected on a stained agarose gel (3\%).

Different isothermal molecule amplification assays have been developed as a rapid, simple, and cost-effective alternative to PCR-based molecule assay since 1990s, which include loop-mediated isothermal amplification assay (LAMP) [22], helicase-dependent amplification assay [23], rolling circle amplification assay [24], nucleic acid sequence-based amplification assay [25], transcription-mediated amplification assay [26], signal-mediated amplification assay [27], self-sustained sequence replication assay [28], ramification amplification assay [29], and RPA assay [30]. Among these assays, RPA has several clear advantages including no initial heating for DNA denaturation, the availability of a simple battery-charged ESEQuant TS2 instrument, and much more easiness in implementing test conditions $\left(37^{\circ} \mathrm{C}\right.$ within $20 \mathrm{~min})$.

In comparison with LAMP assay for detection of PCV2 [31-34], which requires longer time $(60 \mathrm{~min})$ and higher temperature $\left(62-65^{\circ} \mathrm{C}\right)$, RPA assay takes over less than $20 \mathrm{~min}$ at $37^{\circ} \mathrm{C}$ to complete, which makes RPA much simpler and easier to use. The potential defect of PCV2 RPA LFD assay is that it may carryover contamination in the field as it needs to open the tube after amplification. Therefore, precautions should be taken such as careful opening and closing of reaction tubes, frequent changing the gloves, and separating the progress of pre- and post-RPA amplification. Furthermore, replacement of dTTP with dUTP may help prevent such carryover contamination as demonstrated in PCR and LAMP assays $[35,36]$. Our results showed that the developed RPA assay could tolerate base mismatch in some degree as the primes could not completely match with the two PCV2 strains used in our work based on sequence alignment, and it may detect PCV-2 strains in some degree of variability. Wang et al. developed a basic RPA assay for PCV2 detection, recently [37]. The sensitivity and specificity were almost the same as our research, but the results were analyzed using agarose gel electrophoresis and staining limiting the use of it in the field.

\section{Conclusions}

In summary, the PCV2 real-time RPA assay and PCV2 RPA LFD assay described are sensitive and specific for rapid detecting of PCV2 within less than $20 \mathrm{~min}$. The developed RPA assay has the advantage of providing a potential diagnostic tool suitable for routine diagnostic use in a laboratory without complex equipment or in the field, which would greatly assist in epidemiological investigation of PCV2.

\section{Conflicts of Interest}

All the authors declare no conflicts of interest.

\section{Authors' Contributions}

Yang Yang and Zhidong Zhang conceived and designed the project. Yang Yang performed the study and wrote the 
TABLE 3: Comparison of PCV2 real-time RPA assay and PCV2 RPA LFD assay with real-time qPCR assay on clinical samples.

\begin{tabular}{|c|c|c|c|c|c|c|}
\hline \multirow{2}{*}{ Clinical sample } & \multicolumn{2}{|c|}{ Real-time RPA } & \multicolumn{2}{|c|}{ RPA LFD } & \multicolumn{2}{|c|}{ Real-time qPCR } \\
\hline & Positive & Negative & Positive & Negative & Positive & Negative \\
\hline Spleen & 4 & 12 & 4 & 12 & 4 & 12 \\
\hline Inguinal lymph node & 6 & 19 & 6 & 19 & 6 & 19 \\
\hline Tonsil & 9 & 17 & 9 & 17 & 9 & 17 \\
\hline Lung & 7 & 12 & 7 & 12 & 7 & 12 \\
\hline Serum & 5 & 11 & 5 & 11 & 5 & 11 \\
\hline Total & 31 & 71 & 31 & 71 & 31 & 71 \\
\hline
\end{tabular}

TABLE 4: The performance of innuPREP MP basic kit on PCV2 positive samples $(n=31)$ was tested by real-time RPA assay, RPA LFD assay, and real-time $\mathrm{qPCR}$ assay, respectively.

\begin{tabular}{|c|c|c|c|}
\hline Sample name & Real-time qPCR (CT) & Real-time RPA (min) & RPA LFD \\
\hline Spleen 1 & 25 & 7 & + \\
\hline Spleen 2 & 27 & 7 & + \\
\hline Spleen 3 & 29 & 7.3 & + \\
\hline Spleen 4 & 30 & 7.6 & + \\
\hline Inguinal lymph node 1 & 28 & 7 & + \\
\hline Inguinal lymph node 2 & 32 & 8.3 & + \\
\hline Inguinal lymph node 3 & 31 & 8 & + \\
\hline Inguinal lymph node 4 & 29 & 7.6 & + \\
\hline Inguinal lymph node 5 & 26 & 6.3 & + \\
\hline Inguinal lymph node 6 & 26 & 6.6 & + \\
\hline Tonsil 1 & 30 & 8 & + \\
\hline Tonsil 2 & 31 & 8.3 & + \\
\hline Tonsil 3 & 25 & 6.3 & + \\
\hline Tonsil 4 & 25 & 6.6 & + \\
\hline Tonsil 5 & 26 & 6.6 & + \\
\hline Tonsil 6 & 27 & 7.3 & + \\
\hline Tonsil 7 & 27 & 7.6 & + \\
\hline Tonsil 8 & 28 & 7.3 & + \\
\hline Tonsil 9 & 24 & 6 & + \\
\hline Lung 1 & 24 & 6.3 & + \\
\hline Lung 2 & 24 & 6.6 & + \\
\hline Lung 3 & 29 & 7 & + \\
\hline Lung 4 & 22 & 6.3 & + \\
\hline Lung 5 & 22 & 6.6 & + \\
\hline Lung 6 & 30 & 8.3 & + \\
\hline Lung 7 & 30 & 8.6 & + \\
\hline Serum 1 & 32 & 9 & + \\
\hline Serum 2 & 32 & 9.3 & + \\
\hline Serum 3 & 27 & 7.6 & + \\
\hline Serum 4 & 29 & 7.6 & + \\
\hline Serum 5 & 25 & 7.3 & + \\
\hline
\end{tabular}

manuscript. Guozheng Cong and Yingjun Sun participated in preparation of virus and samples. Xiaodong Qin, Yanmin $\mathrm{Li}$, and Zhidong Zhang revised the manuscript.

\section{Acknowledgments}

The research was supported by National Research and Development Program of China (2016YFD0500907) and
Innovation Fund of Chinese Academy of Agricultural Sciences (CAAS), China.

\section{References}

[1] G. M. Allan and J. A. Ellis, "Porcine circoviruses: a review," Journal of Veterinary Diagnostic Investigation, vol. 12, no. 1, pp. 3-14, 2000. 
[2] J. Kim and C. Chae, "Multiplex nested PCR compared with in situ hybridization for the differentiation of porcine circoviruses and porcine parvovirus from pigs with postweaning multisystemic wasting syndrome," Canadian Journal of Veterinary Research, vol. 67, no. 2, pp. 133-137, 2003.

[3] L. Wen, X. Guo, and H. Yang, "Genotyping of porcine circovirus type 2 from a variety of clinical conditions in China," Veterinary Microbiology, vol. 110, no. 1-2, pp. 141-146, 2005.

[4] J. Segalés and M. Domingo, "Postweaning multisystemic wasting syndrome (PMWS) in pigs. A review," Veterinary Quarterly, vol. 24, no. 3, pp. 110-124, 2002.

[5] A.-S. Ladekjær-Mikkelsen, J. Nielsen, T. Stadejek et al., "Reproduction of postweaning multisystemic wasting syndrome (PMWS) in immunostimulated and non-immunostimulated 3 -week-old piglets experimentally infected with porcine circovirus type 2 (PCV2)," Veterinary Microbiology, vol. 89, no. 2-3, pp. 97-114, 2002.

[6] L. J. Guo, Y. H. Lu, Y. W. Wei, L. P. Huang, and C. M. Liu, "Porcine circovirus type 2 (PCV2): genetic variation and newly emerging genotypes in China," Virology Journal, vol. 7, article 273, 2010.

[7] W.-B. Chung, W.-H. Chan, H.-C. Chaung, Y. Lien, C.-C. Wu, and Y.-L. Huang, "Real-time PCR for quantitation of porcine reproductive and respiratory syndrome virus and porcine circovirus type 2 in naturally-infected and challenged pigs," Journal of Virological Methods, vol. 124, no. 1-2, pp. 11-19, 2005.

[8] A. Olvera, M. Sibila, M. Calsamiglia, J. Segalés, and M. Domingo, "Comparison of porcine circovirus type 2 load in serum quantified by a real time PCR in postweaning multisystemic wasting syndrome and porcine dermatitis and nephropathy syndrome naturally affected pigs," Journal of Virological Methods, vol. 117, no. 1, pp. 75-80, 2004.

[9] Q. Liu, L. Wang, P. Willson, and L. A. Babiuk, "Quantitative, competitive PCR analysis of porcine circovirus DNA in serum from pigs with postweaning multisystemic wasting syndrome," Journal of Clinical Microbiology, vol. 38, no. 9, pp. 3474-3477, 2000.

[10] A. L. Hamel, L. L. Lin, C. Sachvie, E. Grudeski, and G. P. Nayar, "PCR detection and characterization of type-2 porcine circovirus," Canadian Journal of Veterinary Research, vol. 64, no. 1, pp. 44-52, 2000.

[11] C. Huang, J.-J. Hung, C.-Y. Wu, and M.-S. Chien, "Multiplex PCR for rapid detection of pseudorabies virus, porcine parvovirus and porcine circoviruses," Veterinary Microbiology, vol. 101, no. 3, pp. 209-214, 2004.

[12] R. Larochelle, M. Antaya, M. Morin, and R. Magar, "Typing of porcine circovirus in clinical specimens by multiplex PCR," Journal of Virological Methods, vol. 80, no. 1, pp. 69-75, 1999.

[13] Y. Yang, X. Qin, W. Zhang, Y. Li, and Z. Zhang, "Rapid and specific detection of porcine parvovirus by isothermal recombinase polymerase amplification assays," Molecular and Cellular Probes, vol. 30, no. 5, pp. 300-305, 2016.

[14] N. Yehia, A.-S. Arafa, A. Abd El Wahed, A. A. El-Sanousi, M. Weidmann, and M. A. Shalaby, "Development of reverse transcription recombinase polymerase amplification assay for avian influenza H5N1 HA gene detection," Journal of Virological Methods, vol. 223, pp. 45-49, 2015.

[15] A. Aebischer, K. Wernike, B. Hoffmann, and M. Beer, "Rapid genome detection of Schmallenberg virus and bovine viral diarrhea virus by use of isothermal amplification methods and high-speed real-time reverse transcriptase PCR," Journal of Clinical Microbiology, vol. 52, no. 6, pp. 1883-1892, 2014.
[16] J. Wang, L. Liu, R. Li, J. Wang, Q. Fu, and W. Yuan, "Rapid and sensitive detection of canine parvovirus type 2 by recombinase polymerase amplification," Archives of Virology, vol. 161, no. 4, pp. 1015-1018, 2016.

[17] A. Abd El Wahed, A. El-Deeb, M. El-Tholoth et al., "A portable reverse transcription recombinase polymerase amplification assay for rapid detection of foot-and-mouth disease virus," PLoS ONE, vol. 8, no. 8, Article ID e71642, 2013.

[18] Y. Yang, X. Qin, G. Wang, Y. Zhang, Y. Shang, and Z. Zhang, "Development of a fluorescent probe-based recombinase polymerase amplification assay for rapid detection of Orf virus Veterinary DNA viruses," Virology Journal, vol. 12, no. 1, article 206, 2015.

[19] Y. Yang, X. Qin, G. Wang, J. Jin, Y. Shang, and Z. Zhang, "Development of an isothermoal amplification-based assay for rapid visual detection of an Orf virus," Virology Journal, vol. 13, no. 1, article 46, 2016.

[20] B.-C. Yang, F.-X. Wang, S.-Q. Zhang et al., "Comparative evaluation of conventional polymerase chain reaction (PCR), with loop-mediated isothermal amplification and SYBR green Ibased real-time PCR for the quantitation of porcine circovirus1 DNA in contaminated samples destined for vaccine production,” Journal of Virological Methods, vol. 191, no. 1, pp. 1-8, 2013.

[21] L.-L. Zheng, Y.-B. Wang, M.-F. Li et al., "Simultaneous detection of porcine parvovirus and porcine circovirus type 2 by duplex real-time PCR and amplicon melting curve analysis using SYBR Green," Journal of Virological Methods, vol. 187, no. 1, pp. 15-19, 2013.

[22] T. Notomi, H. Okayama, H. Masubuchi et al., "Loop-mediated isothermal amplification of DNA," Nucleic acids research, vol. 28, no. 12, p. E63, 2000.

[23] M. Vincent, Y. Xu, and H. Kong, "Helicase-dependent isothermal DNA amplification," EMBO Reports, vol. 5, no. 8, pp. 795800, 2004.

[24] A. Fire and S.-Q. Xu, "Rolling replication of short DNA circles," Proceedings of the National Academy of Sciences of the United States of America, vol. 92, no. 10, pp. 4641-4645, 1995.

[25] J. Compton, "Nucleic acid sequence-based amplification," Nature, vol. 350, no. 6313, pp. 91-92, 1991.

[26] P. Gill and A. Ghaemi, "Nucleic acid isothermal amplification technologies: a review," Nucleosides, Nucleotides \& Nucleic Acids, vol. 27, no. 3, pp. 224-243, 2008.

[27] S. D. Wharam, P. Marsh, J. S. Lloyd et al., "Specific detection of DNA and RNA targets using a novel isothermal nucleic acid amplification assay based on the formation of a three-way junction structure," Nucleic Acids Research, vol. 29, no. 11, article e54, 2001.

[28] J. C. Guatelli, K. M. Whitfield, D. Y. Kwoh, K. J. Barringer, D. D. Richman, and T. R. Gingeras, "Isothermal, in vitro amplification of nucleic acids by a multienzyme reaction modeled after retroviral replication," Proceedings of the National Academy of Sciences of the United States of America, vol. 87, no. 19, article 7797, 1990.

[29] D. Yong Zhang, M. Brandwein, T. Chun Hung Hsuih, and H. $\mathrm{Li}$, "Amplification of target-specific, ligation-dependent circular probe," Gene, vol. 211, no. 2, pp. 277-285, 1998.

[30] O. Piepenburg, C. H. Williams, D. L. Stemple, and N. A. Armes, "DNA detection using recombination proteins," PLoS Biology, vol. 4, no. 7, article e204, 2006.

[31] S. Zhou, S. Han, J. Shi et al., "Loop-mediated isothermal amplification for detection of porcine circovirus type 2," Virology Journal, vol. 8, article 497, 2011. 
[32] K. Zhao, W. Shi, F. Han et al., "Specific, simple and rapid detection of porcine circovirus type 2 using the loop-mediated isothermal amplification method," Virology Journal, vol. 8, article 126, 2011.

[33] H.-T. Chen, J. Zhang, D.-H. Sun et al., "Rapid detection of porcine circovirus type 2 by loop-mediated isothermal amplification," Journal of Virological Methods, vol. 149, no. 2, pp. 264268, 2008.

[34] C. Wang, V. F. E. Pang, F. Lee et al., "Development and evaluation of a loop-mediated isothermal amplification method for rapid detection and differentiation of two genotypes of porcine circovirus type 2," Journal of Microbiology, Immunology, and Infection, vol. 47, no. 5, pp. 363-370, 2014.

[35] M. C. Longo, M. S. Berninger, and J. L. Hartley, "Use of uracil DNA glycosylase to control carry-over contamination in polymerase chain reactions," Gene, vol. 93, no. 1, pp. 125-128, 1990.

[36] E.-J. Kil, S. Kim, Y.-J. Lee et al., "Advanced loop-mediated isothermal amplification method for sensitive and specific detection of Tomato chlorosis virus using a uracil DNA glycosylase to control carry-over contamination," Journal of Virological Methods, vol. 213, pp. 68-74, 2015.

[37] J. Wang, L. Liu, R. Li, and W. Yuan, "Rapid detection of Porcine circovirus 2 by recombinase polymerase amplification," Journal of Veterinary Diagnostic Investigation, vol. 28, no. 5, pp. 574-578, 2016. 

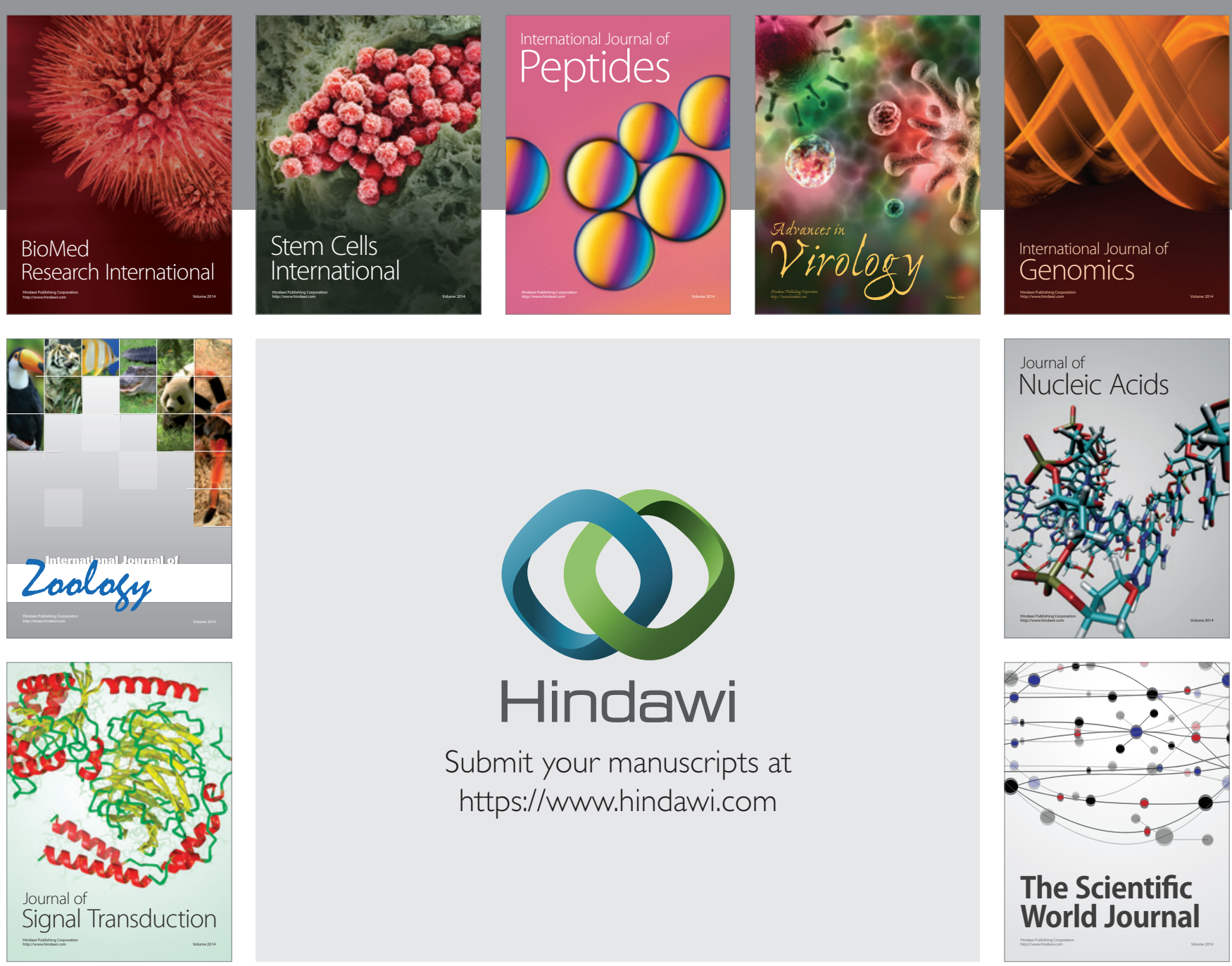

Submit your manuscripts at

https://www.hindawi.com
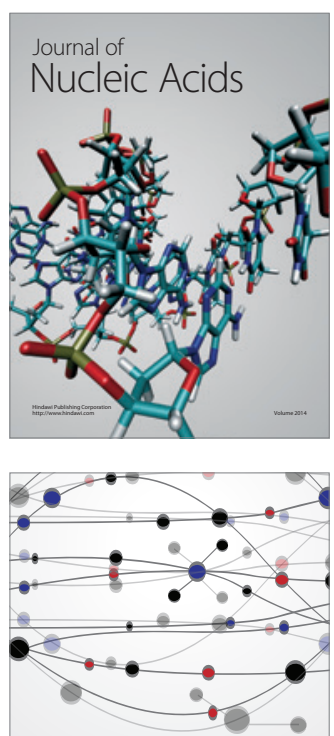

The Scientific World Journal
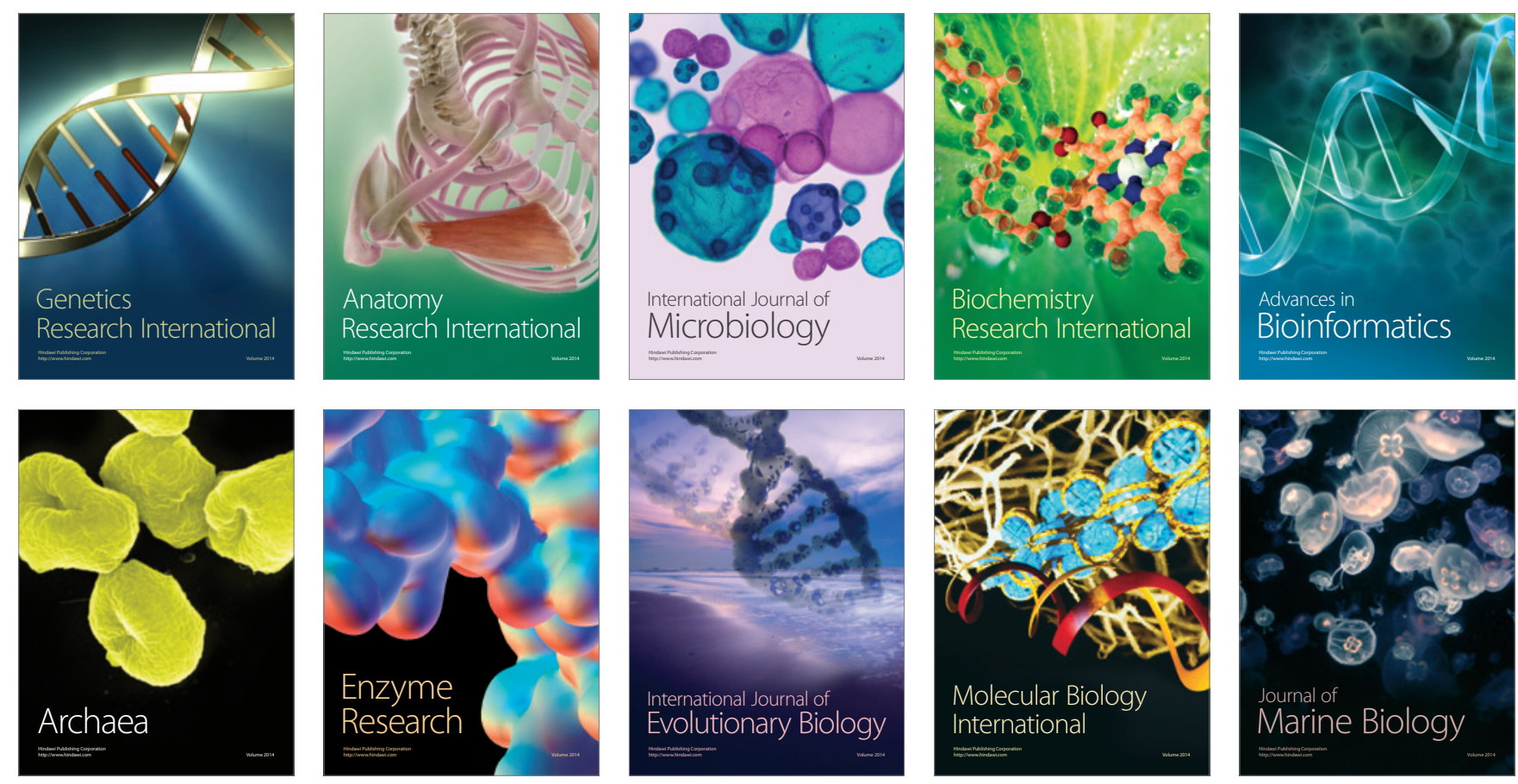